\title{
Spectrum of Diseases among Patients Attending a Breast Clinic at a Tertiary Level Hospital of Bangladesh
}

\author{
Narmeen $\mathrm{T}^{\mathrm{a}}$, Pervez $\mathrm{MMM}^{\mathrm{b}}$
}

\begin{abstract}
Background: Breast problems are a burning health issue for today's women. Breast clinics provide a competent and complete diagnosis for women with any breast symptoms or problems and give appropriate management of the problem. The aim of this study is to determine the disease spectrum among the patients visiting a breast clinic for assistance.

Methods: This was a cross section study of all female patients visiting a breast clinic with breast problems. The study was conducted at BIRDEM General Hospital-2 over a period of 3 years from March 2015 till March 2018. Patients suffering from superficial skin lesions of the breast were excluded. The findings were tabulated and analyzed for frequency of each problem.

Results: A total of 1279 patients visited the breast clinic during the period of March 2015 till March 2018. Among them 1204 patients were selected after considering eligibility criteria. The age of the patients ranged from 15 to 80 years. Ten percent of these patients were asymptomatic and attended the clinic for breast screening. Among the symptomatic patients mastalgia was the most common presentation (36.65\%) followed by fibrocystic disease (22.26\%). Benign Breast lump was seen in $14.96 \%$ patients. Ten percent patients presented with breast abscess. Nipple discharge and ductal ectasia was seen in $2.66 \%$ patients. Breast cancer was found in $2.33 \%$ patients. Other rare entities like milk fistula, giant fibroadenoma were also noted.

Conclusion: Breast clinincs provide comprehensive assistance to both benign and malignant breast diseases. Breast cancer is the leading cause of cancer deaths in females. Breast screening ensures early detection of breast cancer. Besides malignant disease benign breast diseases also cause much morbidity to female health. This study shows the spectrum of patients coming with breast complaints to such a breast clinic.
\end{abstract}

Key words: Breast clinic, malignant breast disease, benign breast disease.

(BIRDEM Med J 2019; 9(1): 11-13)

\section{Introduction}

Breast related problems are a burning health issue in today's woman. Women suffer from various types of breast problems ranging from simple breast pain to breast cancer. Early diagnosis and treatment of breast

\section{Author Information}

a. Dr. Tamanna Narmeen, Assistant Professor, Department of Surgery, BIRDEM General Hospital, Dhaka, Bangladesh.

b. Dr. M M Masud Pervez, Associate Professor, Department of Pediatric Surgery, BIRDEM, General Hospital, Dhaka, Bangladesh.

* Two authors had equal contributions and will be considered as first authors.

Address of correspondence: Dr. Tamanna Narmeen, Assistant Professor, Department of Surgery, BIRDEM General Hospital-2, Dhaka, Bangladesh. Email:tnarmeen@gmail.com

Received: May 8, 2018

Accepted: October 31, 2018 diseases namely breast cancer can save lives and ensure quality life. To ensure health for women breast problems should be addressed properly, and treated accordingly. The goal of a breast clinic is to provide a competent and complete diagnosis for women with any breast symptoms or problems and give appropriate management. Such a breast clinic was started at BIRDEM General Hospital-2 in the year 2015 and has been providing management to women with breast complaints successfully ever since.

Breast undergoes regular changes under the influence of hormones and growth factors throughout the reproductive life of a woman. ${ }^{1}$ Benign breast diseases (BBD) are far more common than the malignant ones. But they are not given enough importance even though around $50 \%$ of women suffer from sign symptoms of 
BBD during their life time. ${ }^{2}$ The physical and psychological sufferings of those females with BBD should not be underestimated and must be addressed properly and managed adequately to decrease morbidity in females. In fact some benign breast lesions can be a predisposing risk factor for developing malignancy in later part of life. ${ }^{2,3}$ So early detection of these benign lesions and identifying the high risk patients is essential for proper and timely intervention of some malignant breast diseases. The objective of this study was to identify the spectrum of breast disease among the females of Bangladesh and find out the frequency of various diseases.

\section{Methods}

A total of 1279 patients diagnosed with breast lesions over a period of three years attended the breast clinic of BIRDEM General Hospital-2. Out of which 1204 patients were included in this study. This is a cross sectional study carried out at the Breast Clinic of BIRDEM General Hospital-2 from March 2015 to March 2018. All female patients included in the study were from 15 to 80 years of age. Initially 1279 patients visited with breast problems. Among them 75 patients were excluded who presented with subcutaneous lipoma, sabeceous cyst, hypertrophic scar and superficial abscess. A detail of patients regarding clinical history and, thorough examination of breast and axilla was followed by investigations. Ultrasonography and / or mammograms were done according to age. MRI was also done in appropriate cases. Fine needle aspiration cytology (FNAC) was advised for patients presenting with lump to confirm the nature of lump. Core biopsy was done in patients with inconclusive FNAC reports.

\section{Results}

A total of 1204 patients visited the breast clinic during the period of March 2015 till March 2018. The age of the patients ranged from 15 to 80 years. Among the patients mastalgia was the most common presentation seen in $440(36.65 \%)$ patients followed by fibrocystic disease (FCD) in 268 (22.26\%) patients. Benign breast lump was seen in $180(14.96 \%)$ patients. One hundred and twenty four $(10.30 \%)$ asymptomatic women attended the clinic for breast screening. One hundred and twenty five $(10.38 \%$ ) patients presented with breast abscess of which 9 patients $(0.74 \%)$ were suffering from granulomatous mastitis with abscess. Nipple discharge and ductal ectasia was seen in $32(2.66 \%)$ patients. Breast cancer patients were 28 (2.33\%). Other rare entities like milk fistula in 6 patients, giant fibroadenoma in 1 patient was also noted. Other patients with lipoma, sabeceous cyst superficial abscess scar also visited the clinic. The different distribution of breast disease and their frequency are shown in Table1.

Table I Distribution and frequency of Breast Diseases

\begin{tabular}{lcc}
\hline Cause of visit & Frequency & Percentage (\%) \\
\hline Mastalgia & 440 & 36.65 \\
Fibro cystic disease & 268 & 22.26 \\
Benign Breast Lump & 180 & 14.96 \\
Breast Screening & 124 & 10.31 \\
Breast Abscess & 125 & 10.38 \\
(nonlactational 79, lactationa & \\
137, granulomatous 9) & & \\
Nipple Discharge & 32 & 2.66 \\
Ca Breast & 28 & 2.33 \\
Milk Fistula & 06 & 0.36 \\
Giant Fibroadenoma & 01 & 0.08 \\
\hline
\end{tabular}

\section{Discussion}

A great number of both benign and malignant lesions occur in breast. BBD include developmental aberrations, inflammatory lesions, epithelial and stromal neoplasms. Breast cancer receives much attention because it is the commonest malignancy in women especially in Western countries; however benign lesions are far more frequent than malignant ones. ${ }^{4-6 .}$

In our study mastalgia was the most common BBD seen in 440 patients (36.65\%). Twenty five percent of referral to breast clinics in West is due to mastalgia and it affects up to $70 \%$ woman at some times during their lives. ${ }^{7}$ Our study showed large number of patients suffering from mastalgia. The second most common disease in our study was fibrocystic disease found in 268 patients $(22.26 \%)$. In three other studies the frequency was $21 \%$, $36 \%$ and $17 \%$ respectively. ${ }^{8-10}$

Murillo et al found 38\% incidence of fibroadenoma in a study of about 698 patients with $\mathrm{BBD}^{8}$, which is not consistent with our study. Khanzada et al showed 27\% incidence of fibroadenoma in a study of 275 patients. ${ }^{9}$ 
Other two studies showed a little higher incidence of $42 \%$ and $45 \%$ respectively. ${ }^{10,11}$ Our study showed a relatively lower incidence of benign breast lumps (14.96\%).

With the advancement of health care women are becoming more and more aware of breast cancer. So a lot of women come for breast screening as screening for malignancy has the scope of early detection and intervention of dreadful disease like breast cancer, thus giving the patient more chance of cure. One hundred and twenty four of total 1204 patients $(10.30 \%)$ visited the clinic for breast screening. Most of them were found normal. Only 1 patient reported positive for malignancy and 1 patient showed suspicious calcification on mammogram. The next entity was breast abscess and acute mastitis (125 patients). This was most commonly observed in non-lactating females. As the study area was a specialized hospital like a diabetic hospital breast abscess in non-lactating females was a common presentation. In non-diabetic females lactational mastitis is more prevalent. Among the total patients suffering from acute mastitis with abscess 9 were suffering from granulomatous mastitis that had to be treated with antitubercular chemotherapy also. Though granulomatous mastitis is rare in developed countries, this is not uncommon in Asian countries. The overall incidence is less than $0.1 \%$ of all breast lesions in developed countries and $2-3 \%$ in developing countries. ${ }^{12}$ Only over 37 patients of them had lactational breast abscess. Barton et al found acute bacterial mastitis common at any age but most frequently in lactating breasts. ${ }^{13}$

In our study 32 patients (2.66\%) had nipple discharge mostly associated with duct ectasia which can mimic invasive carcinoma clinically. ${ }^{14}$ It usually presents with nipple discharge, palpable subareolar mass, pain, nipple inversion or retraction. ${ }^{15}$ In our study 28 (2.33\%) of all breast patients were diagnosed as carcinoma breast. Various study showed that the highest incidence of breast cancer was in Northern America and Oceania; and the lowest incidence in Asia and Africa. ${ }^{15}$ One patient presented with giant fibroadenoma.

\section{Conclusion}

Breast disease of various kinds is a burning health issue in females worldwide. Among them breast cancer is the gravest. Cancer breast is the fifth leading cause of cancer deaths. Thus breast cancer demands much attention in screening, early diagnosis and appropriate treatment intervention to ensure proper and timely management of breast cancer patients. But BBD is far more frequent than malignancy. In our study mastalgia is the commonest breast symptom. Fibrocystic disease is the next common problem. Benign breast lump like fibroadenoma also occurs in great number. It is essential to address these benign breast problems properly and provide appropriate management to reduce female health morbidity. Breast clinics can provide assistance to women with breast diseases by addressing benign breast problems and early diagnosis and appropriate management of malignant ones.

Conflict of interest: Nothing to declare.

\section{References}

1. Bhoopal S, Ramanujam R. Benign breast diseases: experience at a teaching hospital in rural India. Int J Res Med Sci 2013; 1: 73.

2. Naveen N, Mukherjee A, Mahajan V. A clinical study of benign breast disease in rural population. J Evol Med Dent Sci 2013; 2: 5499-511.

3. Hari S, Shukla SK. Benign breast disorders in non-Western populations: Part II. Benign breast disorder in Indian World J Surg 1989; 13: 746-49.

4. Caleffi M, Filho DD, Borghetti K. Cryoablation of benign breast tumors: evolution of technique and technology. Breast 2004; 13: 397-407.

5. Kelsey JL, Gammon P. Epidemiology of breast cancer. Epidemiol Rev 1990; 12: 228-40.

6. Cole P, Elwood J, Kaplan SD. Incidence rates and risk factors of benign breast neoplasms. Am J Epidemiol 1978; 108: $112-20$.

7. Murillo O B, Botello H D, Ramirez M C, Garcia FJ. Benign breast diseases: clinical, radiological and pathological correlation. Ginecol Obstet Mex 2002; 70: 613-18.

8. Khanzada TW, Samad A, Sushel C. Spectrum of benign breast diseases: Pak J Med Sci 2009; 25: 265-68.

9. Rashid R, Haq SM, Khan K, Jamal S, Khaliq T, Shah A. Benign breast disorders, a clinicopathological study. Ann Pak Inst Med Sci 2005; 1: 187-90.

10. Ali K, Abbas MH, Aslam M, Abid KJ, Khan AZ. Frequency of benign breast diseases in female patients with breast lumpsa study at Sir Ganga Ram Hospital. Ann King Edward Med Coll 2005; 11: 526-28.

11. Chaudhary IA, Qureshi SK, Rasul S, Bano A. Pattern of benign breast diseases. J Surg Pak 2003; 8: 5-7

12. Jalali U, Rasul S, Khan A, Baig N, Khan A, Akhter R. Tuberculous mastitis. J Coll Physicians Surg Pak 2005; 15: 234-37.

13. Barton AS. The Breast. In: Pathology. Rubin E Farber JL. 2nd edi. Philadelphia: JB Lippincort Co; 1994: 978.

14. Guray M, Sahin AA. Benign Breast Diseases: Classification, Diagnosis, and Management. The Oncologist 2006; 11: 435-49.

15. Ferlay J, Soerjomataram I, Ervik M, Dikshit R, Eser S, Mathers C, et al. Cancer Incidence and Mortality Worldwide: IARC Cancer Base No 11. GLOBACON 2012; 1(1). 